TITLE: DEVELOPMENT OF A CRYOGENIC HEAT PIPE

AUTHOR(S): $\quad$ F. Coyne Prenger, MEE-13

Walter F. Stewart, MEE-13

James E. Runyan, MEE-13

SUBMITTED TO: $\quad$ Cryogenic Engineering Conference

July 12-16, 1993

Albuquerque, NM

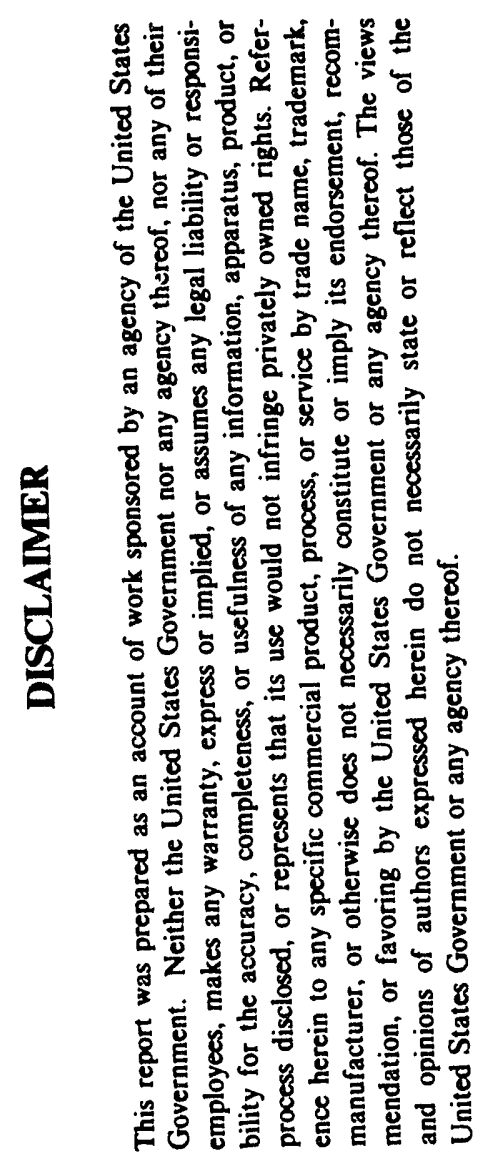

By acceptance of this article, the publisher recognizes that the U.S. Govemment retains a nonexclusive, royalty-free license to publish or reproduce the published form of this contribution, or to allow others to do so, for U.S. Government purposes.

The Los Alamos National Laboratory requests that the publisher identify this article as work performed under the auspices of the U.S. Department of Energy.

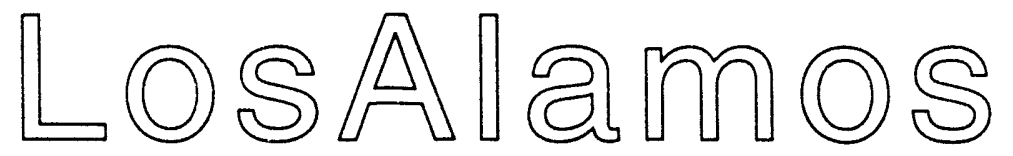

FORM NO. 836 R4 ST NO. $26295 / 81$

\section{Los Alamos National Laboratory Los Alamos, New Mexico 87545}

\section{MASTER}

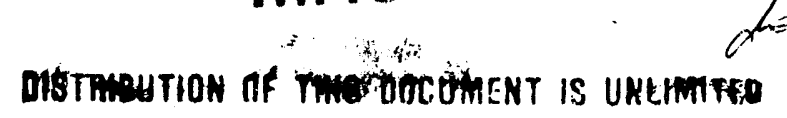




\title{
DEVELOPMENT OF A CRYOGENIC HEAT PIPE
}

\author{
F. C. Prenger, W. F. Stewart and J. E. Runyan \\ Advanced Engineering Technology \\ Los Alamos National Laboratory \\ Los Alamos, NM 87545
}

\begin{abstract}
Heat pipe operating characteristics can be used to advantage in cryogenic systems. Diode operation of the heat pipe, the ability to conduct heat in one direction only, is useful in protecting the heat load if the heat sink temperature rises above the load temperature. Because of this, the heat pipe can be made to act as a thermal switch. A screened-wick, inverted-artery, cryogenic heat pipe was designed, fabricated, and tested. The tests were first conducted with hydrogen and then with oxygen as the working fluid. Heat pipe performance limits were measured as a function of operating temperature, and startup from both the supercritical and the frozen state was demonstrated. The heat pipe was designed to operate as a thermal diode, and transient tests were used to determine the turndown ratio. The heat pipe test results were correlated with the Los Alamos heat pipe computer code and good agreement was obtained between the predicted and measured performance. The heat pipe was developed for spacecraft sensor cooling applications. Test results show significant performance advantages over solid conductors.
\end{abstract}

\section{INTRODUCTION}

Heat pipe operating characteristics can be used to advantage in cryogenic systems. ${ }^{1-3}$ In particular, the heat pipe's high effective thermal conductivity can increase cryocooler system efficiency by reducing the temperature span of the cooling system. By reducing the $\Delta \mathrm{T}$ between the heat load and the cryocooler the minimum operating temperature of the cryocooler can be higher, resulting in higher system efficiency. In addition, the high effective thermal conductivity allows greater separation distance between the load and the cryocooler. Diode operation of the heat pipe, the ability to conduct heat in one direction only, is useful in protecting the heat load if the heat sink temperature rises above the load temperature. And because of this, the heat pipe can be made to act as a thermal switch. The relatively low axial heat flux capability of cryogenic heat pipes renders their power transport capacity less significant than that of higher temperature heat pipes; however, from a weight standpoint, the cryogenic heat pipe still outperforms solid conductors. ${ }^{4}$

The thermophysical properties of cryogenic working fluids are significantly different from their $300 \mathrm{~K}$ and above counterparts. Both the surface tension and the latent heat of vaporization are low compared with other working fluids. This has an adverse effect on the axial heat transport capability. The low surface tension also contributes to poor wick priming in a $1-\mathrm{g}$ environment. The liquid-vapor density ratio of cryogenic working fluids is much smaller than that for other heat pipe working fluids. This has a significant influence on 
the internal design of the heat pipe, especially for zero-g operation, where the cross-sectional areas for liquid and vapor flow are determined by the density ratio. In general, the liquid flow area in cryogenic heat pipes is larger than that for other working fluids. Finally, the low liquid thermal conductivity of the cryogens can result in significant radial temperature gradients if the liquid layer or the wick structure is too thick. These differences in the thermophysical properties of cryogenic working fluids significantly affect the cryogenic heat pipe design.

Priming of the wick structure must occur upon cooldown from the supercritical state. At standard conditions cryogenic working fluids are supercritical and, upon cooldown, formation of the liquid phase occurs at the critical point. Provision must be made to insure that the liquid will consistently prime the wick structure. Most heat pipe working fluids are introduced into the heat pipe either as a solid or a liquid. Wick designs for these conditions may not be adequate for priming from supercritical.

The low thermal conductivity of the cryogenic working fluids in the liquid phase can easily lead to large radial temperature gradients in the heat pipe if liquid layers become thick at the inside wall of the heat pipe. Therefore, the wick structure must be designed to minimize liquid buildup at the heat pipe wall. A thin distribution wick is also required to minimize the radial thermal resistance.

The cryogenic heat pipe must also be designed to withstand the large internal pressure that occurs at ambient temperature $(300 \mathrm{~K})$. The heat pipe is usually charged with the cryogen at a temperature between 77 and $300 \mathrm{~K}$, depending on which cryogen is used. After charging the heat pipe, storage at room temperature is likely. The internal pressure can, therefore, be significantly higher than the charging pressure. Unfortunately, this requires the use of greater wall thicknesses and stronger materials. It also favors the use of small diameters for the heat pipe container.

\section{HEAT PIPE DESIGN}

In addition to the constraints discussed above, which are dictated by the operating temperature and the properties of the cryogen, the heat pipe should have other features suitable for cryogenic applications. In particular, a bendable geometry is desirable, that is, bendable at least once after filling, to facilitate installation. The heat pipe should also be capable of diode operation or one-way heat transfer. If the axial temperature difference across the heat pipe is reversed, the heat transfer in the reverse direction should be very small. This also requires that there be low axial conduction in the heat pipe wall. Using a homogeneous material, it is difficult to obtain both a low axial thermal conductivity and a high radial thermal conductivity. The problem is further complicated by the large wall thickness required to withstand the high internal pressure at the $300 \mathrm{~K}$ storage temperature. These requirements also have a significant influence on the internal design of the heat pipe, which is discussed in the following section.

Several possible wick configurations were considered and evaluated based on heat pipe performance, ease of fabrication, and bendability. Heat pipe performance, based on maximum power transport capability, was determined using the LANL computer code for two general wick types: the homogeneous wick, and the artery wick. Two types of homogeneous wicks were considered: a screened type and a sintered type. These were compared with a single artery design. The artery heat pipe has significantly better performance than either homogeneous design. The high liquid pressure drop resulting from the flow through the homogeneous wick has an adverse effect on heat pipe performance. The artery design, which is a form of composite wick, has a much lower liquid pressure drop because the liquid is not required to flow axially through the wick material but, instead, flows inside a tube formed by the screen. Because of the poor performance of the homogeneous wick, an artery or composite wick design was pursued.

Several artery configurations were considered. In all cases the vapor flow channels are within the arteries and the liquid flow is external to the arteries. The inverted artery configuration was adopted for the cryogenic heat pipe design to control the amount of liquid at the heat pipe wall. The configuration shown in Fig. 1 was chosen for the final design because it provided redundant vapor and liquid flow passages. In addition, it minimized the liquid inventory at the wall and provided for vapor arteries of unequal size, which insured a larger vapor flow area in case of overfill of the heat pipe (excess liquid will collect in the smaller artery). 


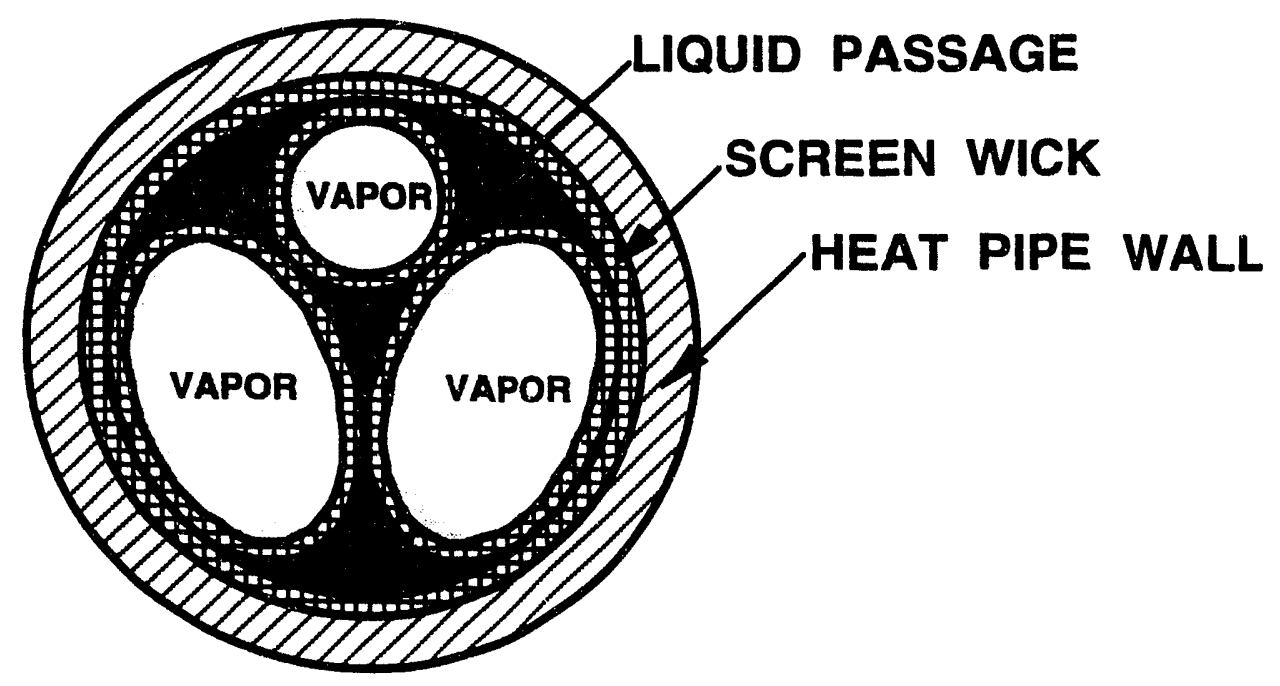

Figure 1. Heat pipe configuration selected for fabrication and testing.

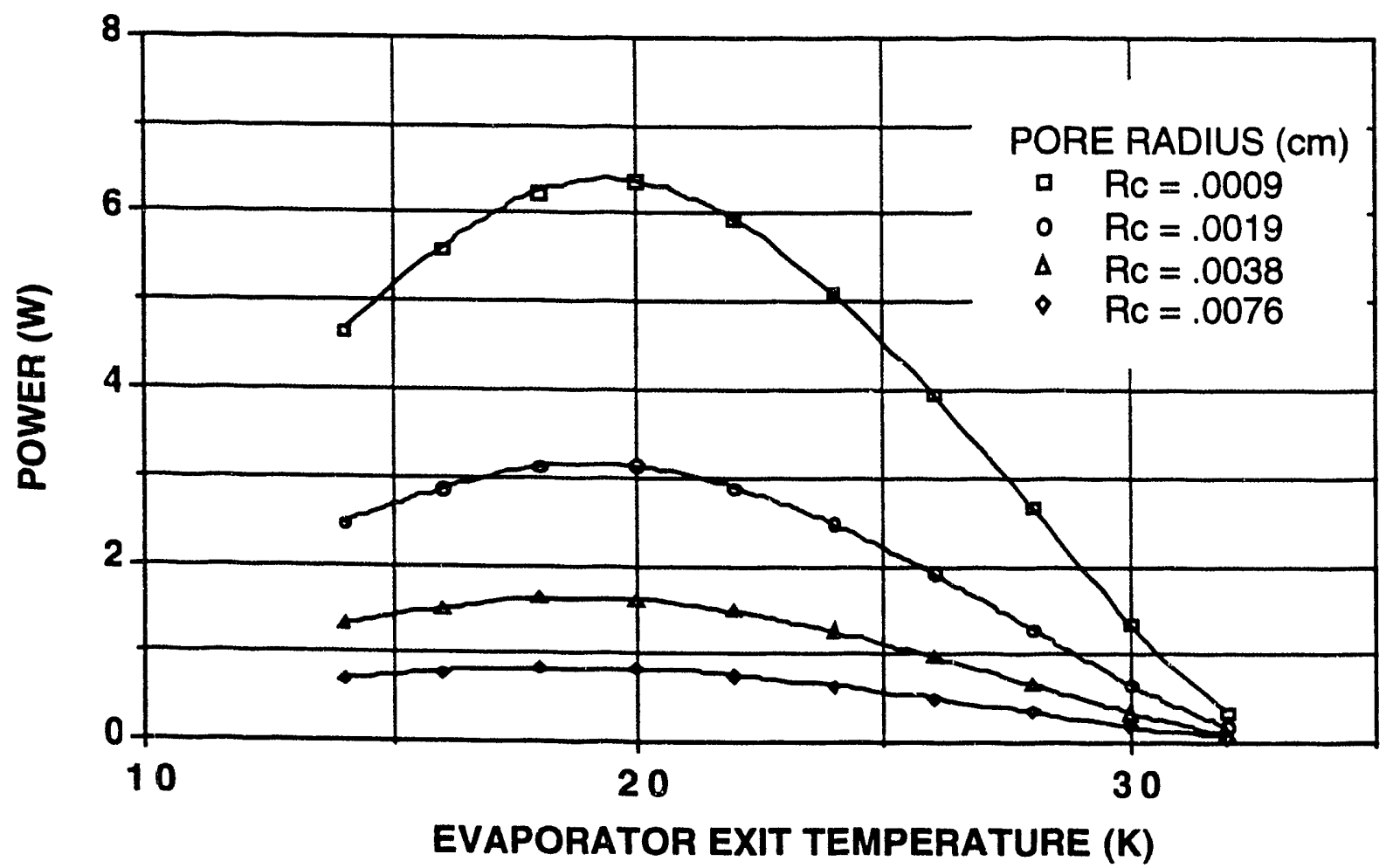

Figure 2. Effect of screen pore size on heat pipe performance with hydrogen working fluid.

The heat pipe that was fabricated for testing was constucted from 9.5-mm-o.d. stainless steel tubing with a wall thickness of $0.89 \mathrm{~mm}$. The evaporator, condenser, and adiabatic section of the heat pipe each had a length of $100 \mathrm{~mm}$. The arteries were fabricated from multiple layers of 400 mesh stainless steel screen. The screened arteries form a relatively flexible internal structure, that can be bent without distortion. The use of sintered wicks or a grooved-wall design would have produced a rigid structure and would have prevented bending after fabrication. The wick had a permeability of $29 \mu \mathrm{m}^{2}$ and a pore radius of $16 \mu \mathrm{m}$. 
A fine mesh screen was selected to provide the smallest pore size consistent with commercially available materials. The performance of the heat pipe is sirongly influenced by the effective capillary radius of the wick structure. Figure 2 shows the heat pipe capillary limit, the maximum power the heat pipe can transport with a given capillary pressure difference, as a function of temperature, for several pore sizes. The smaller the pore radius, the larger the capillary pressure difference, and the higher the heat pipe performance limit. Figure 2 also illustrates the effect of temperature on heat pipe performance. For hydrogen working fluid the maximum performance is achieved at $20 \mathrm{~K}$. This maximum is determined by the variation of thermophysical properties with temperature.

The heat pipe performance limit curve is an envelope defining the operating region of a particular heat pipe design. Points below the curve are stable operating points, whereas operation above the curve is not possible. The performance envelope is a combination of several performance limits. including the sonic, capillary, and boiling limits. Also of significance in Fig. 2 is the operating temperature range of the heat pipe, which is between 14 and about $33 \mathrm{~K}$. This is a significant fraction of the triple point-to-critical-point range for hydrogen. This wide operating temperature span is a unique characteristic of cryogenic heat pipes.

The heat pipe was charged with hydrogen to a pressure of $8.3 \mathrm{MPa}$ at a temperature of $156 \mathrm{~K}$ using an ethanol alcohol-liquid nitrogen bath.

\section{TEST APPARATUS}

The cryogenic heat pipe test apparatus consisted of a heat sink (a Gifford-McMahon gas-cycle refrigerator), a calorimeter connecting the heat pipe condenser to the heat sink, and a cryostat for thermal isolation.

The calorimeter was a cylindrical copper block with a mounting flange matching the flange on the second stage of the gas-cycie refrigerator. The condenser of the heat pipe was inserted into the calorimeter in an oversized hole along the axis of the copper cylinder. A copper-loaded grease (crycon) was used to provide a low-resistance thermal joint at the heat pipe-calorimeter interface. The copper calorimeter provided a nearly isothermal environment for the heat pipe condenser. The calorimeter and heat pipe are shown schematically in Fig. 3. Silicon diode thermometers were used to measure heat pipe wall temperatures and the calorimeter temperature. The thermometer locations are shown in Fig. 3. Two electric
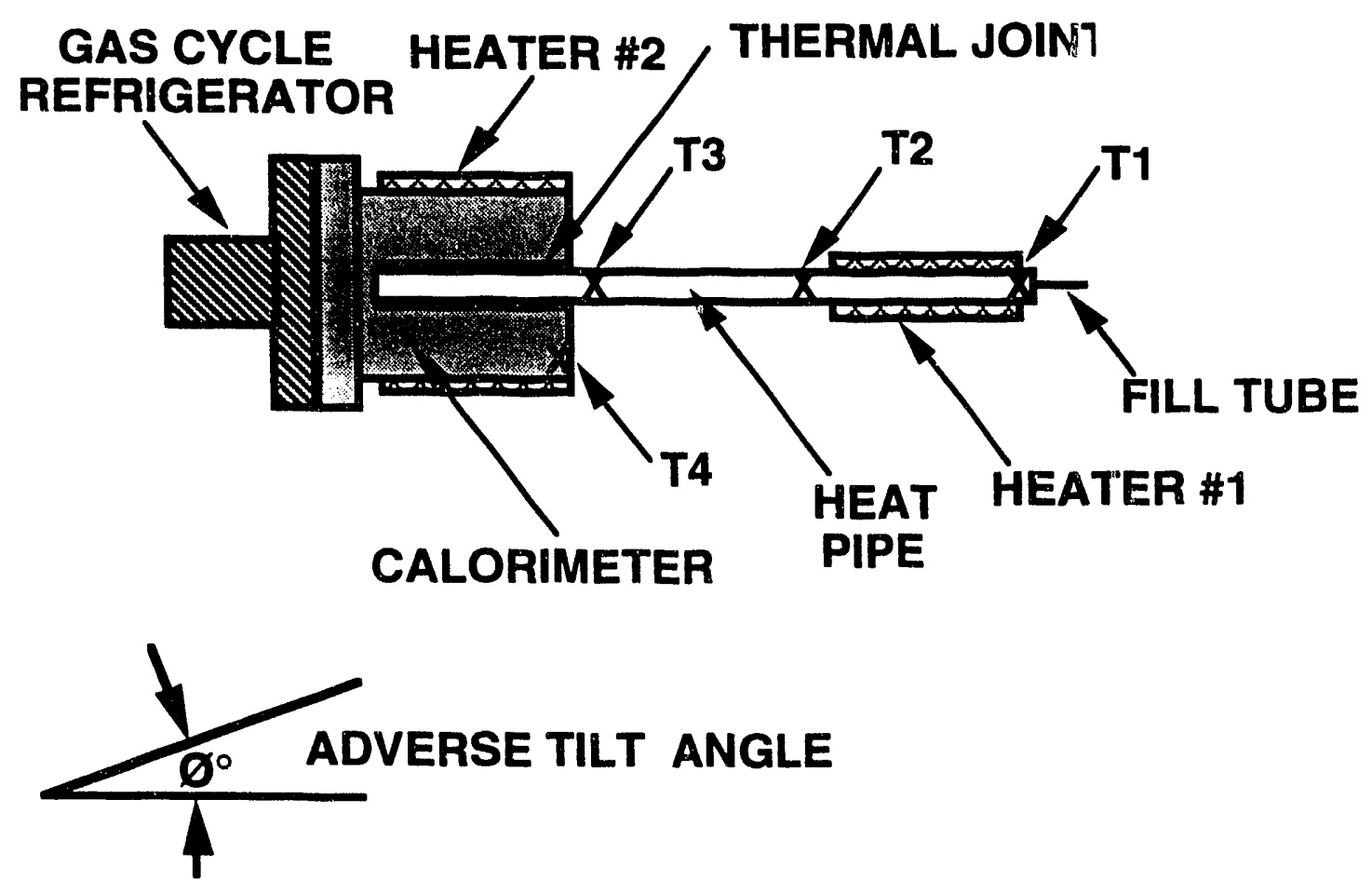

Figure 3. Schematic of the cryogenic heat pipe test apparatus showing heaters and thermometers. 
heaters were used for the test. One heater was wrapped directly on the heat pipe evaporator and provided the power transported by the heat pipe. The second heater was attached to the calorimeter and supplied auxiliary heat to the system. The auxiliary heat provided control of the heat pipe operating temperature by changing the load on the gas-cycle refrigerator. Therefore, both operating temperature and power were controlled by electric heaters. The heaters were made by attaching multiple wraps of Manganin wire directly to the surface using General Electric (GE) varnish.

\section{PERFORMANCE TESTING}

The heat pipe performance limit is defined as the maximum power that the heat pipe can transmit under nearly isothermal conditions. Exceeding this power limit results in an interruption of the circulation of the working fluid and subsequent dryout of the evaporator region. With an evaporator no longer supplied with liquid, the heat pipe cannot continue to transmit power by internal fluid circulation and the axial temperature gradient increases as axial conduction becomes the primary heat transfer mode.

The performance limit is dependent on operating temperature, and the break-down in internal circulation can be caused by a numter of factors. Of primary interest to this study is the capillary limit, which is reached when the sum of the liquid and vapor pressure drops exceeds the capillary pressure generated in the heat pipe wick, or

$$
\Delta \mathrm{P}_{\text {cap }} \geq \Delta \mathrm{P}_{\text {liquid }}+\Delta \mathrm{P}_{\text {vapor }}
$$

In screened-wick heat pipes, the capillary pressure is a function of the surface tension of the working fluid and the pore diameter of the wick. The principal reason for using an artery design is to enable the wick to have a small pore size, while, at the same time, a low axial pressure drop in the liquid. This is especially important for cryogenic heat pipes where the surface tension is poor. Obtaining the heat pipe performance limit as a function of temperature is the primary requirement in evaluating any heat pipe design.

The power transmitted by the heat pipe is determined by the power applied to the evaporator by the external heater. This same power must then be removed at the heat sink through the calorimeter. If heat removal capability is limited, the heat pipe can be tilted with the evaporator up, a negative tilt angle, to force the liquid to return to the evaporator against gravity. The additional pressure drop in the liquid resulting from the hydrostatic head can be treated as an apparent load on the heat pipe because of superposition of the pressure terms. This is a convenient way to increase the load on the heat pipe without increasing the heat load to the heat sink. This technique was used in the performance testing of the cryogenic heat pipe.

\section{HYDROGEN RESULTS}

The heat pipe tests traversed a sequence of steady-state operating points to determine the heat pipe performance limits. The power throughput and operating temperature were controlled by the evaporator and calorimeter heaters. During normal operation of the heat pipe, the axial temperature difference was less than $1 \mathrm{~K}$. Upon reaching a performance limit, the axial temperature difference increased significantly, indicating interruption of working fluid circulation. Plots of temperature versus time revealed the increase in axial temperature difference and were used to determine the performance limits for the given operating temperature.

Figure 4 shows the measured heat pipe performance limits at adverse tilt angles of $5^{\circ}$ and $30^{\circ}$. Also shown is the predicted performance using the LANL heat pipe computer code at these tilt angles for three and two operating liquid arteries respectively. Because of the poor surface tension of the hydrogen, not all of the liquid arteries were able to prime in the 1$\mathrm{g}$ test. Of the four liquid arteries, three primed at $-5^{\circ}$ tilt angle and only two primed at $-30^{\circ}$ tilt angle. The change in the number of arteries primed can be explained by the difference in 


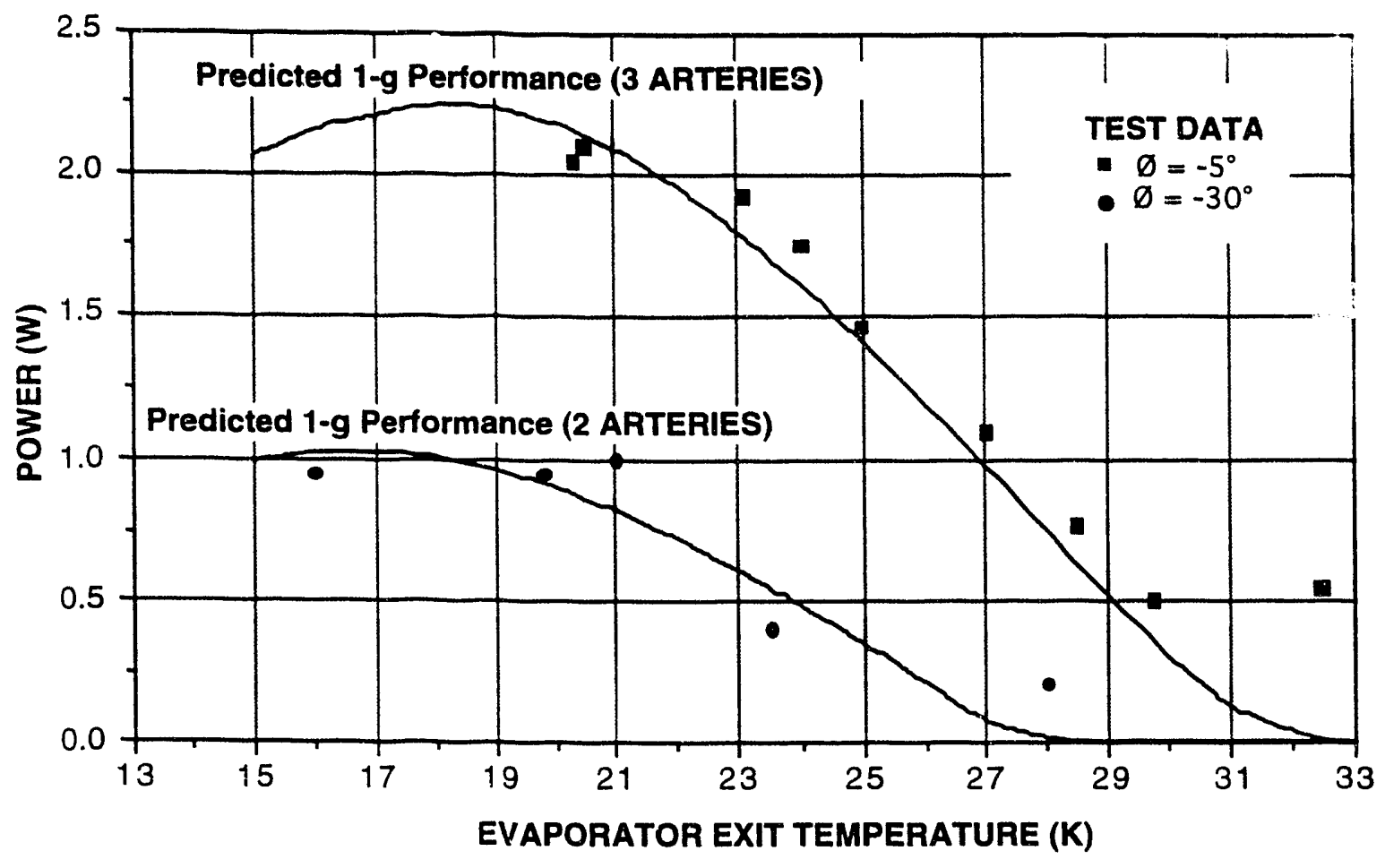

Figure 4. Heat pipe performance with hydrogen working fluid.

the hydrostatic head at the two tilt angles. The measured performance limits shown in Fig. 4 illustrate that the heat pipe is operational over most of the temperature range between the triple point $(13.8 \mathrm{~K})$ and the critical point $(33.0 \mathrm{~K})$. This operating characteristic is unique to cryogenic working fluids.

Figure 5 shows the predicted performance in zero-g if all four liquid arteries are operational. The problem of priming in a $1 \mathrm{~g}$ field would not be a factor in zero-g operation. The maximum heat pipe performance is predicted to be $6.5 \mathrm{~W} / \mathrm{cm}^{2}$ at $18.5 \mathrm{~K}$ based on a vapor flow area of $0.5 \mathrm{~cm}^{2}$.

\section{OXYGEN RESULTS}

Based on the performance results obtained using hydrogen as the heat pipe working fluid, it was decided to test the heat pipe at higher temperatures using oxygen as the working fluid. Operating temperatures of 60 to $65 \mathrm{~K}$ were of particular interest. The heat pipe was charged with oxygen to a pressure of $5.7 \mathrm{MPa}$ at a temperature of $156 \mathrm{~K}$ using an ethanol alcohol-liquid nitrogen bath. The heat pipe was tested in the same test configuration used for the hydrogen tests.

Figure 6 shows the test data for adverse tilt angles of $10^{\circ}, 20^{\circ}$, and $30^{\circ}$. The results are in good agreement with predictions using the heat pipe computer code. In this case all input to the code was specified by the heat pipe geometry, except for the wick permeability, which was treated as an adjustable parameter and was determined using one of the heat pipe operating points. Results from the code are shown as solid lines. The code assumes that four arteries are operating, which indicates complete priming of all liquid passages. At an adverse tilt angle of $10^{\circ}$ the axial heat flux of $12 \mathrm{~W} / \mathrm{cm}^{2}$ at $63 \mathrm{~K}$ was measured. Figure 6 also shows the predicted heat pipe performance under zero-g conditions. The maximum axial heat flux is $21 \mathrm{~W} / \mathrm{cm}^{2}$ at $85 \mathrm{~K}$. 


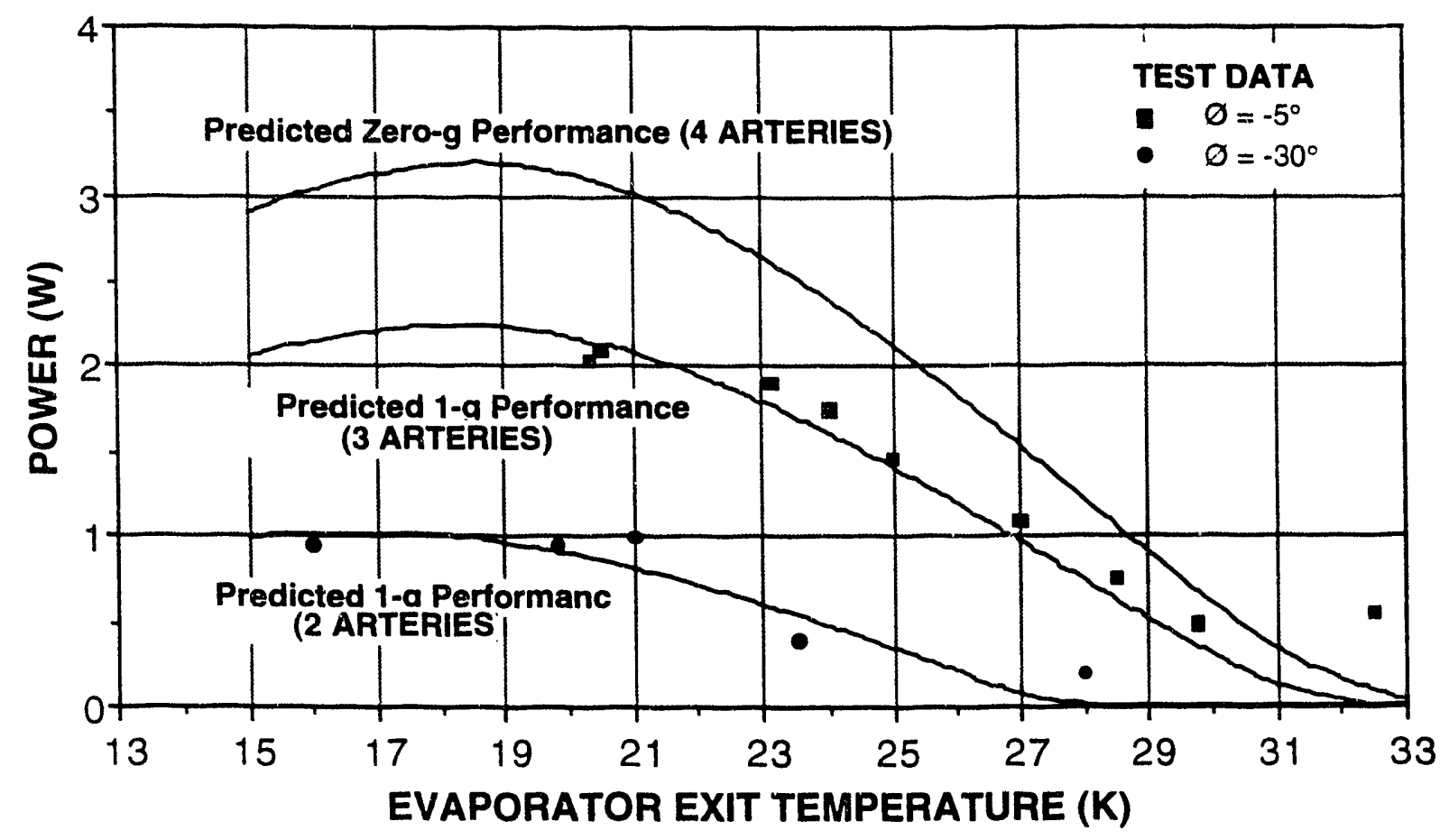

Figure 5. Predicted performance of hydrogen heat pipe in zero-g compared with one-g test data.

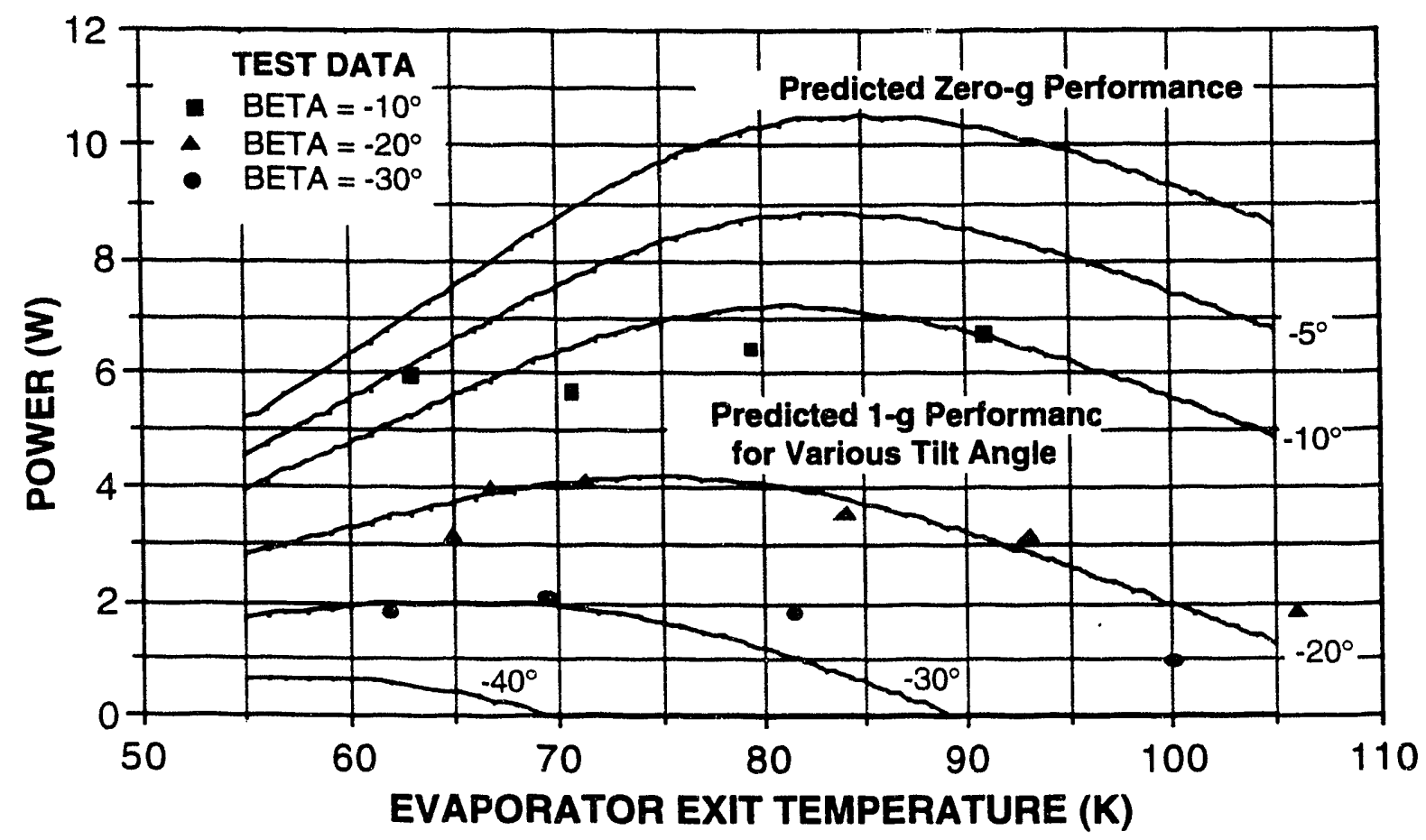

Figure 6. Predicted performance of oxygen heat pipe with four arteries in zero-g compared with 1-g test data.

\section{STARTUP FROM SUPERCRITICAL STATE}

Because of their low operating temperature, cryogenic heat pipes have different startup requirements compared with higher temperature heat pipes. While most heat pipes must start up with the working fluid initially in the solid or liquid state, cryogenic heat pipes normally start up with the working fluid initially supercritical. 
Successful startup of the hydrogen heat pipe occurred with a heater power of $0.2 \mathrm{~W}$ at the evaporator, indicating proper priming of the liquid arteries upon cooldown to onerating temperature. The heat pipe was also started with the working fluid initially in the rrozen state. With $0.1 \mathrm{~W}$ of power applied to the evaporator, the evaporator inlet showed overheating until a sufficient quantity of working fluid melted to establish circulation in the evaporator. The heat pipe then became nearly isothermal.

\section{DIODE OPERATION}

The heat pipe was designed to operate as a thermal diode, a device that transfers heat in one direction only. This operating characteristic prevents the heat load from being warmed by the heat sink if the heat sink temperature becomes greater than the heat load temperature. To achieve diode operation, the heat pipe wick is closed at the evaporator end but not at the condenser end. The condenser end of the wick is, therefore, not able to generate a significant capillary pressure difference and, hence, is not able to support much working fluid circulation when the heat pipe is heated from the condenser end. Some liquid flow can occur within the screens forming the arteries, but the flow resistance of the screen is very large because of the high tortuosity and low permeability.

Several transient tests were run to determine the extent of reverse flow in the heat pipe and, hence, the power transmitted in the reverse direction, from condenser to evaporator. The transient tests were conducted by heating the calorimeter to a temperature above that of the evaporator and then measuring the evaporator response. The axial temperature difference, shown in Fig. 7, is a measure of the heat pipe conductance. In Fig. 7, the axial $\Delta T$ is shown as a function of tilt angle. For large adverse tilt angles, the flow is reduced and the axial temperature difference increases. These data can be used in conjunction with the heat pipe model to predict the reverse conduction in zero-g as a function of the operating temperature. These results are shown in Fig. 8. The curve labeled "forward direction" is the zero-g performance under normal operation, or evaporator heated, and the curve labeled "reverse direction" is the zero-g performance if the condenser is heated. These data, for hydrogen working fluid, show a turndown ratio, power transmitted in the forward direction divided by power transmitted in the reverse direction, of approximately 10 . The turndown ratio is a function of the heat pipe length, where the effective length of this heat pipe is 20 $\mathrm{cm}$, with longer lengths giving higher turndown ratios.

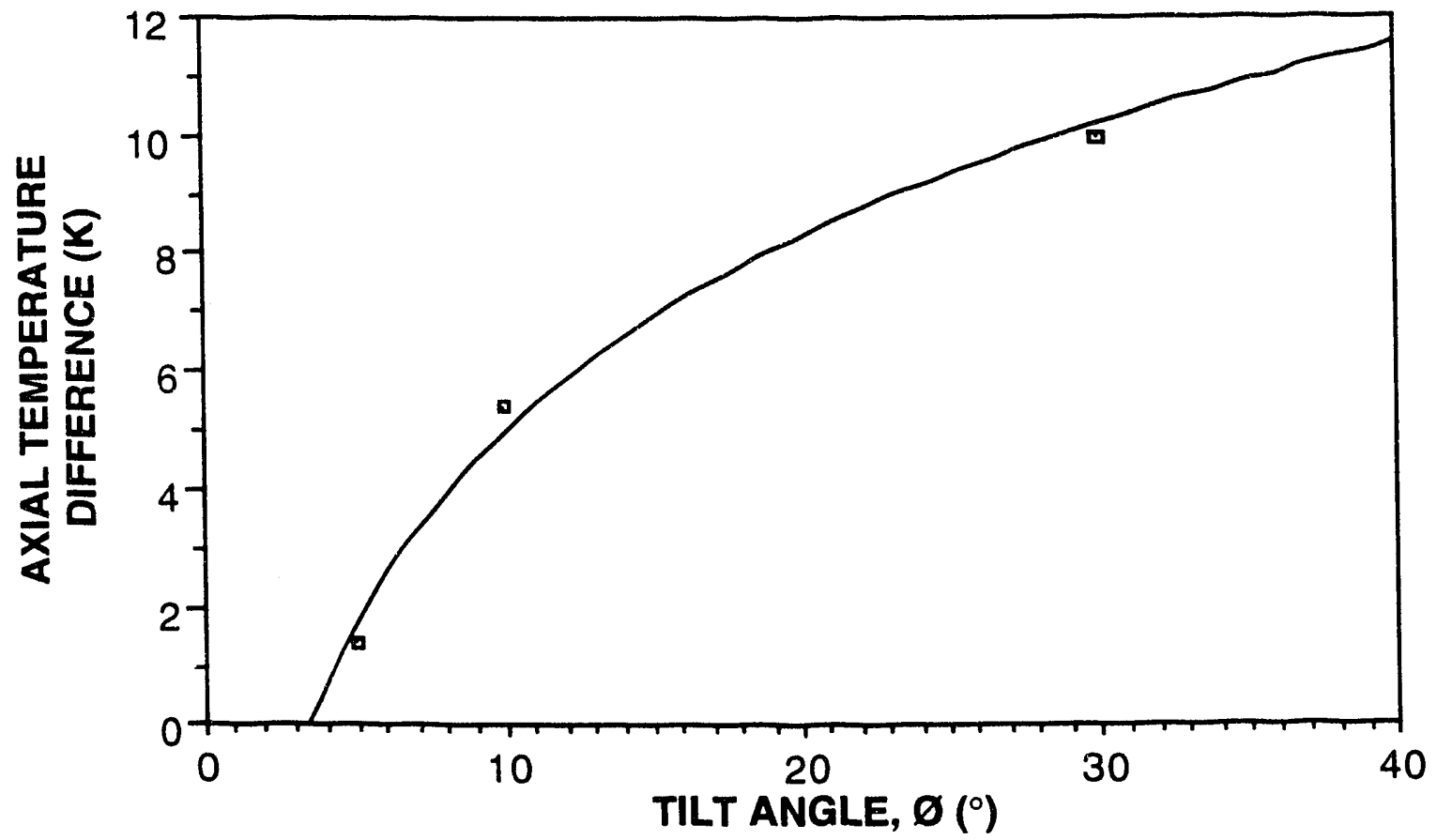

Figure 7. Axial temperature difference during transient response of the heat pipe with condenser heated. 


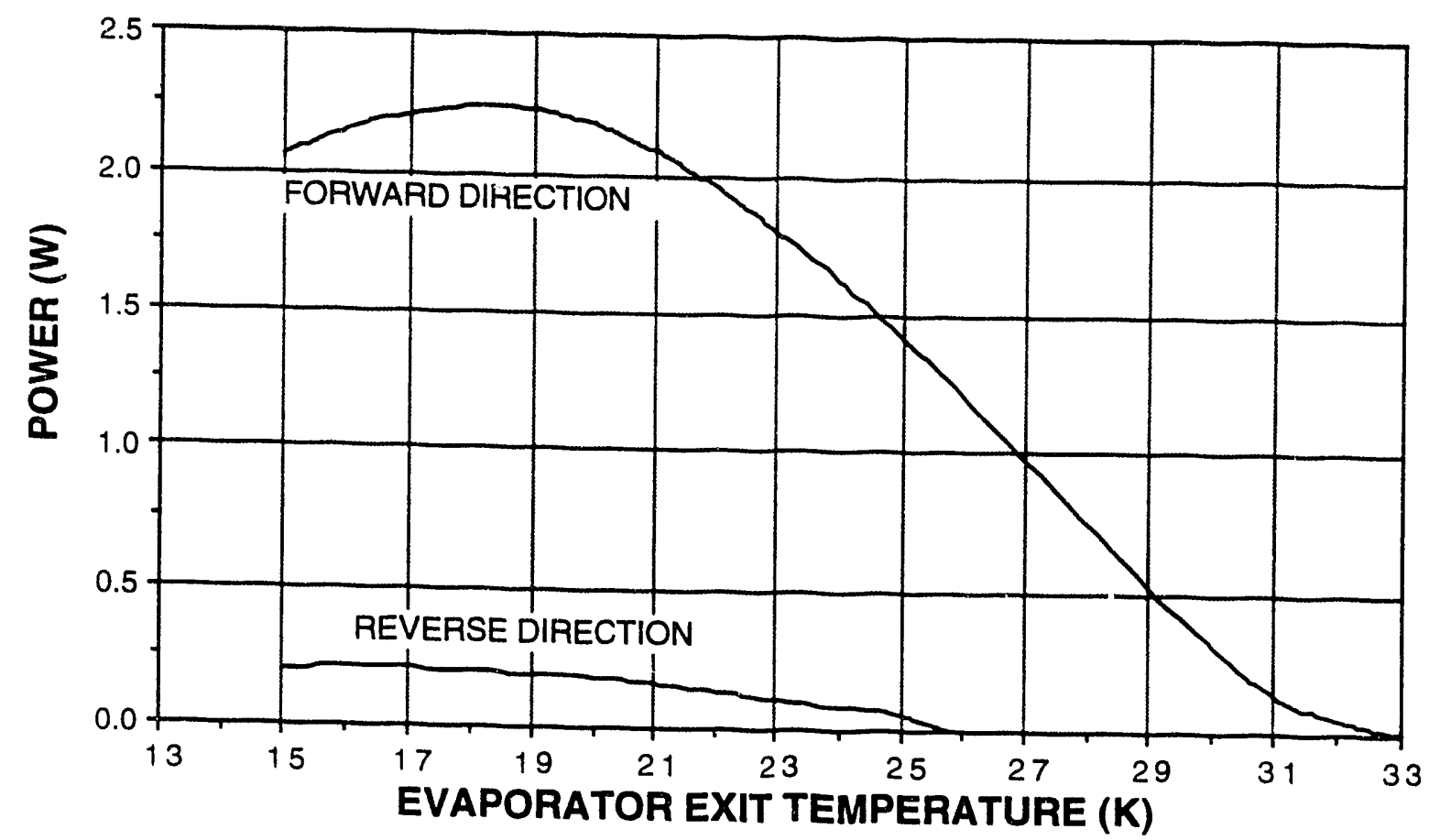

Figure 8. Predicted heat pipe performance for forward and reverse mode based on measured transient response data.

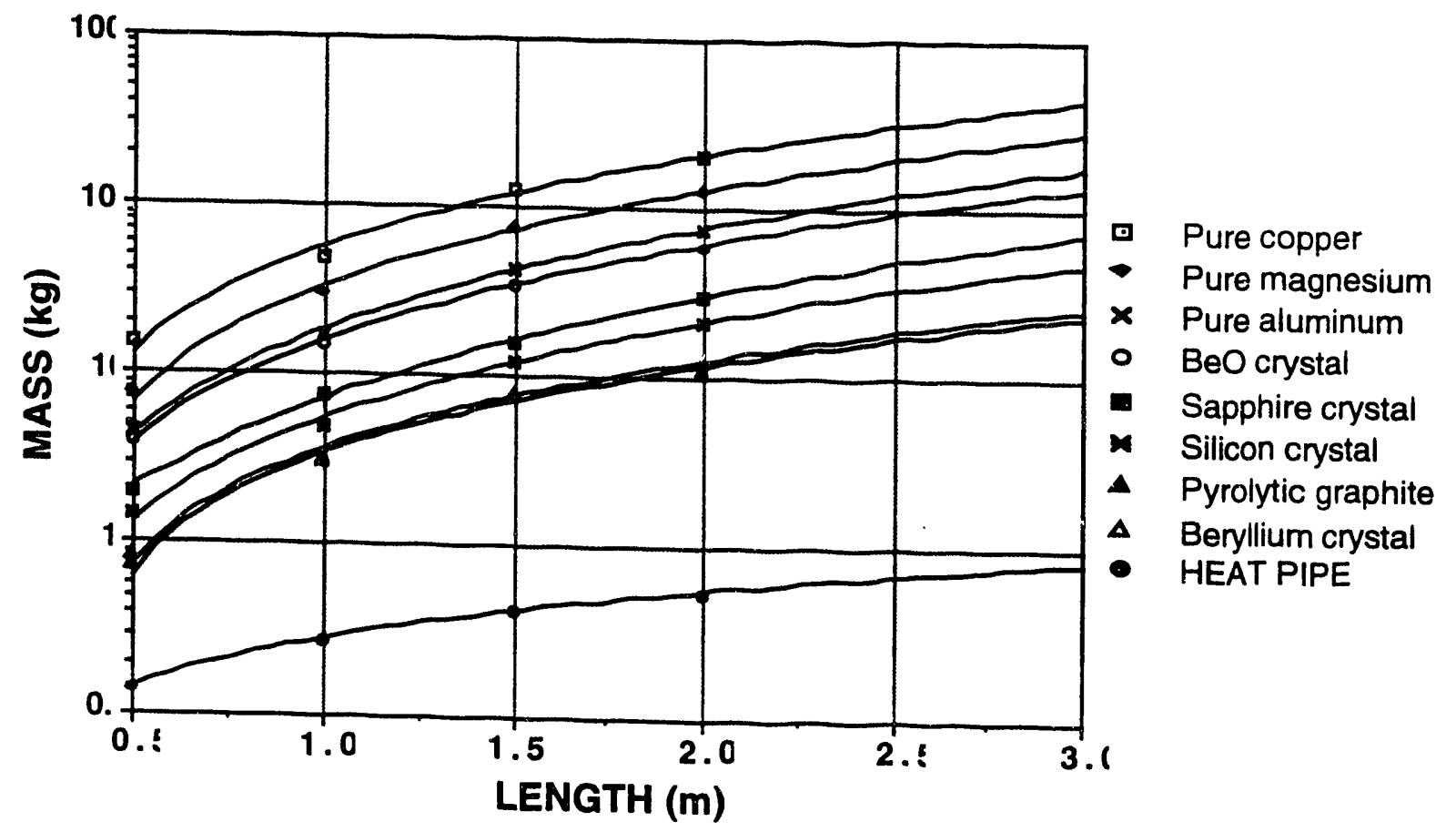

Figure 9. Mass of the heat pipe vs mass of a solid conductor carrying a 5-W heat load with a temperature drop of $1 \mathrm{~K}$ at a temperature of $60 \mathrm{~K}$.

\section{COMPARISON WITH SOLID CONDUCTORS}

The principal advantage of the heat pipe is to provide an efficient conductive link that also operates as a thermal diode, conducting heat in only one direction. In Fig. 9 a comparison is made between the heat pipe and several solid conductors. The data are 
for a $5 \mathrm{~W}$ heat load at $60 \mathrm{~K}$ and an axial temperature drop of $1 \mathrm{~K}$. The results show ti...t the heat pipe mass is less than one-tenth that of the best solid conductor. Also, tis :olid conductors do not behave as diodes as the heat pipe does.

\section{CONCLUSIONS}

Based on the design, fabrication, and testing of a screened-wick, cryogenic heat pipe, we conclude the following:

1. Screened-wick, artery heat pipes are well adapted to cryogenic working fluids and show a significant performance advantage over solid conductors at cryogenic temperatures.

2. Fabrication of wicks for small diameter heat pipes is feasible provided adequate tooling is developed. Spot welding is satisfactory for wick sealing.

3. Cryogenic heat pipes can be successfully started from either the supercritical or the frozen state.

4. Measured heat pipe performance correlates well with results from the heat pipe computer code; however, in 1 -g tests the low surface tension of the working fluid can cause incomplete priming of the liquid arteries.

5. In our test heat pipe, thermal diode operation gave a turndown ratio of approximately 10 . The turndown ratio is strongly dependent on the heat pipe geometry and significant improvement is possible.

6. The heat pipe is operational over nearly the complete temperature range from triple point to critical point.

\section{REFERENCES}

1. A. Basiulis and G. L. Fleishman, "Passive Cryogenic Devices and Thermal Management," IEEE Transactions, pp. 1456-1457 (1989).

2. G. P. Peterscn and G. L. Compagna, "Review of Cryogenic Heat Pipes in Spacecraft Applications," AIAA J. of Spacecraft, V 24, pp. 99-100 (1987).

3. T. H. Sun and R. C. Prager, "Development of a Switchable Cryogenic Heat Pipe for Infrared Detector Cooling," AIAA/ASME Thermophysics and Heat Transfer Conference, Boston, Massachusetts (1974).

4. J. A. Jones, "Cryogenic Mixed Fluid Application Study and Computer Code Development," JPL Report No. D-7977 (1990). 

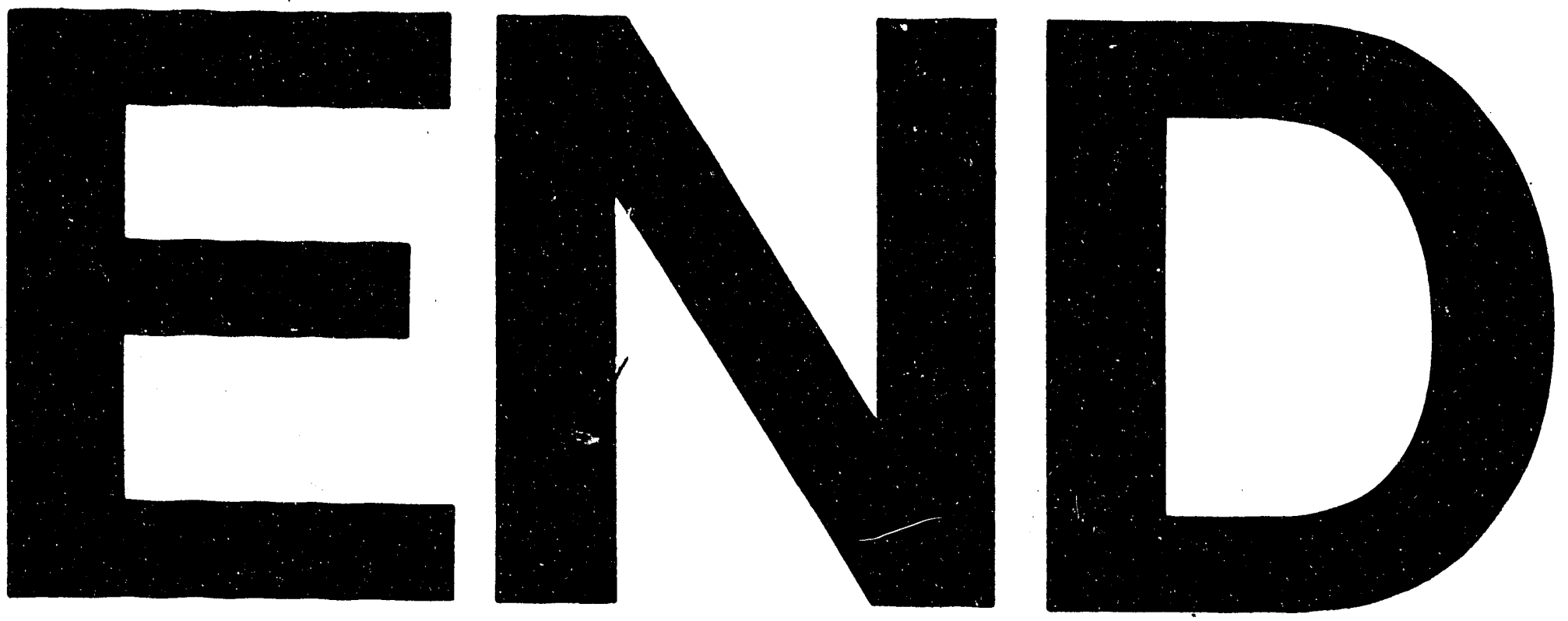

1

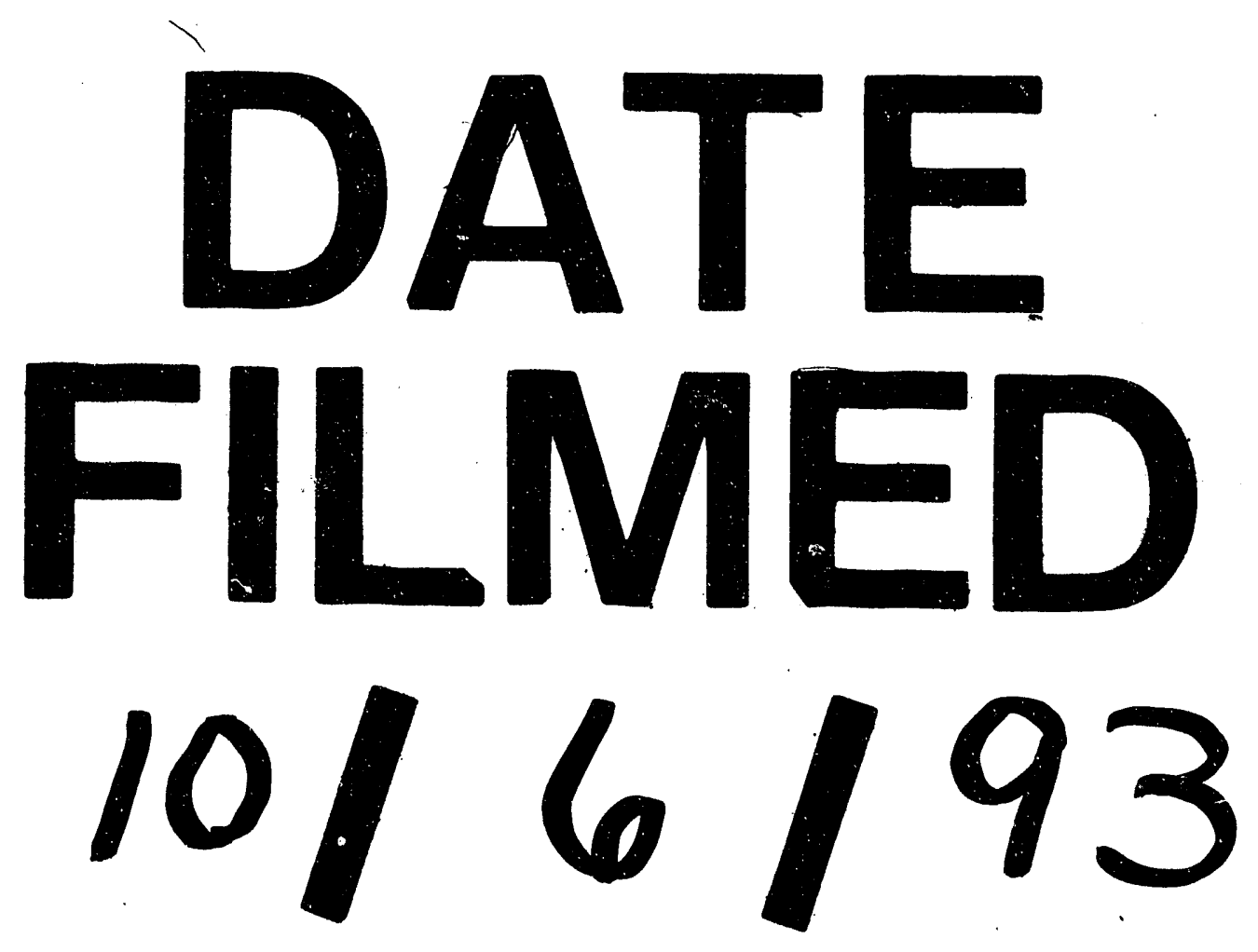

